\title{
The problem of the diabetic patient in developing countries
}

\author{
N.A. Serantes \\ Chairman of the South and Central American Regional Council of the International Diabetes Federation, University of Buenos Aires, \\ Buenos Aires, Argentina
}

Identification and therapeutic care of approximately 30 million diabetic patients presently living in developing countries represent at least as important challenges to current diabetology as basic, clinical or epidemiological research or the application of sophisticated diagnostic and therapeutic methods to diabetes care.

There have been valuable contributions to this topic in recent years. These include several Congresses on Diabetes in the Tropics and in Underdeveloped Countries, and a number of papers in specialized journals such as the IDF Bulletin, the journal published by the Vuk Vrhovak Institute in Zagreb, Yugoslavia, the World Health Organization publications, and the Bulletin of the Latin American Diabetes Association [1-5], among others. In additions, the International Diabetes Federation (IDF) has recently created a Steering Committee for Diabetes in Developing Countries.

This paper is not meant to be just one more to add to this already long list. It intends to reconsider the matter from the viewpoint of a diabetologist who lives in one of those developing countries and who has, over the past few decades, maintained close contact with diabetologists and members of health care centers in countries with varying degrees of under-development.

The problems of diabetic patients living in developing countries recall Tattersall's reflection [6] on "The geriatric diabetic, a neglected subject?" The difference, however, lies in the fact that for elderly, multimorbid diabetic patients, various health and welfare services in Europe have been able to draw attention to their problems, i. e. to overcome the negligence. The diabetic patients we are so concerned with, on the contrary, are immersed in a context of underdevelopment which has been difficult to overcome. In more recent years, this difficulty has been further exacerbated by a widening of the gap between the underdeveloped and developed world [7].

In spite of this basic pessimism, it is our responsibility to be well aware of the situation and to analyse the best possible way of setting up the human and technical resources available in the most effective manner.

\section{Difficulties in studying the problem}

\section{Lack of information}

The available epidemiological data on the prevalence or incidence of diabetes mellitus in underdeveloped countries are fragmentary and non-representative (with the exception of easily accessible and attractive places, such as the various Pacific Islands). Thus, it is impossible to compute such figures in continents such as Latin America where, according to Vargas Tentor [8], 38\% of the population has no access to medical care. In Bangladesh, a country with 93 million inhabitants where a systematic and persevering effort to improve diabetic care is being made, only 39,000 patients out of an estimated total of more than a million diabetics are registered [9].

In many instances, epidemiological data are derived from small subsections of the population; to extrapolate from such highly selected information to the entire population is misleading and may be harmful. In many developing countries, one can find well-equipped, prestigious and very modern health care centers quite similar to those operating in Europe or the United States of America. Not unexpectedly, the performance statistics of such diabetes centers are comparable, independent of their location.

For instance, in Santiago (Chile), in Rio de Janeiro (Brazil), in Havana (Cuba), in Montevideo (Uruguay) and in some Argentine maternity wards and centers, the peri-natal death rate for the offspring of diabetic mothers is less than 3\%. This figure is not much different than those of the leading units specializing in the care of diabetic pregnancies between Karlsburg, Copenhagen and Belfast. However, it is quite obvious, at least to everyone living in these countries, that only a very small percentage of pregnant diabetic patients has any access to the above specified centers; and that the outcome of their pregnancies (for mother and offspring) is characterized by extremely higher rates of both morbidity and mortality. Exact figures, such as neonatal death rates, 
are not available for the entire population (or representative parts of the population), since for any health care system the quality of health care delivery and the available treatment will invariably correlate with the capacity of the system to evaluate its own performance (or even to have it evaluated from the outside).

\section{Heterogeneity of health care delivery systems in developing communities}

Afgaonkar [10] has listed the predominant problems identifiable in all underdeveloped areas as: (a) low educational level, often including illiteracy; (b) lack of facilities (for evaluation and research); (c) inappropriate nutrition and (d) apathy and indifference. Calderon [11] has added to the list "communication problems between various members of health care teams and patients". He has further commented that there is a basic need to deal with health care, agriculture/nutrition and education of the population in one global approach. However, it seems important to point out that substantial differences exist among the different developing countries as well.

It is impossible to apply the same methods for improvement of diabetes care in countries with an average annual income of 150 US dollars per capita, one physician per 10,000 inhabitants and an illiteracy rate of $70 \%$, as it is in others where the gross annual income per capita reaches 1,500 US dollars, where one physician is available per 1,000 inhabitants and illiteracy is only $15 \%$. It is also necessary to bear in mind the differences in underdevelopment between different areas of the same country, e.g. between Nairobi and the interior of Kenya, or between the south and northeast of Brazil. Finally, in almost every developing country, an economic and political upper-class minority has been formed which absorbs an excessive proportion of the medical resources, thus further reducing the means available to the general population. In this context, it might be of interest to identify the particular economic and political status of those patients who are examined by retinofluoresceinography or who are treated by haemodialysis in these countries.

\section{Growing urbanization}

The drift (or rush) toward the cities represents a sociological phenomenon typical of the second half of the 20th century in many developing countries, especially in Southeast Asia and Latin America. This mass movement has had profound effects with regard to diabetes care.

Urbanization permits better access to medical care and a decrease in illiteracy but, on the other hand, in many cases it results in nutritional deterioration as soon as the economic system of subsistence characteristic of underdeveloped rural life disappears. A study carried out in Argentina [12], where both development and underdevelopment coexist, has shown that the unsatisfied basic needs of some urban groups in the surroundings of the city of Buenos Aires are comparable to those of the poorer marginal areas of the interior of the country.

\section{Problems of diabetes care in developing countries}

\section{Prevalence}

There are but a few studies on the prevalence of diabetes which have been conducted with adequate epidemiological rigour. Almost all of them have been carried out in countries or cities with relatively low degrees of underdevelopment. For example, Santiago (Chile) [13] reported a prevalence of $5.2 \%$ in inhabitants above 20 years of age. In contrast, diabetes prevalence of about 2\% was described in Bangladesh [9]. An assessment carried out in an underdeveloped area of Argentina identified $3.46 \%$ of the population above 20 years as known diabetics, whereas in a rural community of the same region the figure was a mere $0.2 \%$ [14]. Recent data from The People's Republic of China have indicated a diabetes prevalence of $1.0 \%$ to $1.2 \%$ for the large cities and of about 0.3 to $0.5 \%$ for the rural areas $[15,16]$.

A study on diabetes prevalence or incidence upon a representative and significant sample of a population is expensive. In order to justify the expenditure, the country and its health care system must also be prepared to treat and care for the diabetic patients of that community. In this context, one is faced with a twofold question: to what extent should we carry out costly epidemiological surveys and statistics, thus diverting funds which are urgently required for improvement of diabetes diagnosis, care and rehabilitation? Is it worth studying the statistical problem of diabetes unless, for at least $30 \%$ of the patients, adequate care can be provided?

\section{Low prevalence of Type 1 (insulin-dependent) diabetes mellitus}

The scarce data on the prevalence on Type 1 (insulindependent) diabetes mellitus that are reported for developing countries unanimously indicate that this form of diabetes is extremely rare. For the Dominican Republic a prevalence of 21 in 100,000 has been reported [17]; likewise in Beijing only a minute percentage of known diabetic patients might be classified as Type 1 .

A crude way of estimating the number of insulin-dependent diabetic patients in a given community is based on insulin consumption, assuming an average daily consumption of 40 units of insulin per patient. During a panel discussion on diabetes in Latin American held at the 5th Latin American Congress on Diabetes, Estrade (personal communication) reported that Argentina used 22.5 units of insulin per inhabitant per year; Brazil, 
Chile, Uruguay, Venezuela and the Dominican Republic used between 10 and 14 units; Ecuador and Peru used 2.3 units; and Bolivia used only 0.3 units per inhabitant per year. These figures differ from those of industrialized countries such as West Germany, with a consumption of approximately 100 units per inhabitant per year. This apparent north to south increase in the estimated prevalence of insulin dependent diabetes might be the mirror image of the respective, but unexplained, gradual rise in the incidence and prevalence of Type 1 diabetes from southern or northern Europe $[18,19]$.

More likely, however, is an explanation based upon differences in the rate of underdiagnosis in childhood and adolescence. If, during polyuria or reappearance of enuresis, or in the presence of vomiting or excessive loss of weight, glucosuria remains undiscovered, the patient will soon die without his or her diabetes ever having been diagnosed.

In Salta (Argentina), a subtropical underdeveloped area with a quite effective system of primary health care and a special unit to take care of infantile diabetes, 34 cases of childhood diabetes were reported in a population of 95,000 under 15 years of age. For a comparable population only a few hundred kilometers away, a similarly undeveloped area without an effective health care system reported the estimated prevalence of insulin-dependent diabetes (based upon the consumption of insulin) as extremely lower. Accordingly, Mngola [20] and others have attributed the very low number of known Type 1 diabetic patients in developing countries largely to failure in diagnosing the disease for many patients before they succumb to it.

\section{The problem of malnutrition}

Caloric-protein malnutrition in most developing countries represents the major problem of mankind, except for the possibility of nuclear warfare and other deteriorations of the earth's environment. Unequal distribution of food, adequate nutrition and hygiene describe a global problem of social injustice. From the 20 million tons of soy beans sent annually from developing countries to the industrialized world to be used as fodder, several hundred million people could daily eat $30 \mathrm{~g}$ of protein of high biological value.

The present lack of access to nutrition in developing countries affects diabetes in different ways:

a) It prevents the majority of patients from following dietary recommendations usually made by physicians as part of treatment. In a study we carried out in Quito Ecuador together with a group of local dieticians, a simple diabetes diet with only $16 \mathrm{~g}$ of animal-derived proteins with no more than 1,800 total calories was equivalent in price to one third the total salary of an average family of six members.

b) Malnutrition is frequently related to infection. Chi-Zhu-Seng [21] reported that infection was the cause of hospitalization for $23 \%$ of the diabetic patients in a clinic in Shanghai as compared with $9 \%$ in a hospital in Japan and $6 \%$ in the Joslin Clinic in the United States of America. Infections often require the temporary use of insulin, an expensive medicine as yet difficult to obtain in some areas of the world.

c) Malnutrition also leads to an increase in intercurrent illnesses, which results in a higher frequency of hospitalizations in areas with a chronic need of hospital beds.

Finally, particular diabetes syndromes of developing countries have been identified which are related to malnutrition or to the ingestion of special foods such as cassava, which contains a toxic compound for the pancreatic $B$ cell in undernourished people. These various syndromes, such as Type 1 diabetes reported by Jones in Jamaica [22], Type Z by Zuidema [23] in Java, Type K by Mngola [24] in Kenya, and many others [25], require further investigation.

\section{Medical care for diabetic patients}

To improve nutrition, to provide treatment to mother and child, to struggle against communicable diseases (parasitosis infections, etc.) are priorities as far as the health of diabetic patients is concerned. The relative importance of these basic matters becomes more urgent the more underdeveloped the country is and the lower the resources alloted to health care. In countries where urbanization increases and life expectancy rises, direct measures of treatment become more important because of the increasing prevalence of diabetes and the frequency of complications.

However, under any circumstances the care of the diabetic patients is mandatory. The diabetologist and the public health officer should base their cooperation on the realities of the given situation, designing health care plans appropriate to the circumstances of each country, starting off with limited action if necessary. Even a "pilot" project, modest as it may be, with the resources ready to extend it into a sustained effort which aims to provide the utmost diabetes care feasible, is desirable. Unfortunately, that is often far from the ideal. It appears obvious that such efforts would be more successful if initiated on a local, decentralized basis, rather than as part of a national or international long-term project. Furthermore, such a struggle against diabetes in developing countries should avoid any attempt to copy European or North American health care organization schemes.

There is general agreement that, although diabetes is not a transmissible disease, it ought to be integrated into the system of primary health care. This care consists of a central level; an intermediate level; and a team of primary health care professionals which should include a general practitioner and primary health care officers of the same culture as that of the population requiring care. As part of these professionals' many duties, they 
are instrumental in identifying and educating diabetic patients. The existence of the "medicine man" who possesses supernatural powers to prevent or cure diseases is a reality in almost all underdeveloped communities. It is important to have his cooperation (provided he accepts some fundamental rules of medicine) because his role as a natural leader of the community can strengthen the action of the primary health care team. With the help of health care officers and nurses/dieticians, the general practitioner in this team is responsible for patients with Type 2 diabetes mellitus. Patients with Type 1 diabetes or difficult syndromes are referred for further treatment and evaluation to intermediate or central levels, temporarily or permanently. Because of difficulties in communication and transportation, the primary care physician will very often have to take care of the entire diabetic population. The Associacion Latino-Americana de Diabetes has distributed throughout Latin America tens of thousands of booklets with the Rules (accepted standards) of diabetes care in Spanish and Portuguese [26-27] meant for the non-specialized physician. Furthermore, following a meeting of experts held in Lima, Perú in 1982 [28], a methodology for education and training of the entire primary health care team was established.

Sometimes the effectiveness of a local Diabetes Association correctly steered and dynamically managed can make up for government shortcomings and deficiencies. One such example is the activity of the National Institute of Endocrinology and Nutrition [29] of the Dominican Republic, which has become a center of high scientific prestige and has organized a very efficient peripheral network of diabetes care even though it is not strictly organized according to the standards of primary health attention established by WHO.

More difficult and controversial is the job description of the diabetologist working at the central level and the problems involved in carrying out his duties. These problems are not encountered in cities where there are high-level university centers such as New Delhi, Shanghai, Nairobi or Rio de Janeiro. The problems develop when the diabetologist is isolated in a hospital which represents the central level in an area of one to several million inhabitants. Working under such conditions, his priorities have to be altogether different from those of a Swedish, Canadian or Yugoslavian diabetologist.

The first stage is common to any physician in the world: to keep up-to-date with scientific news and, what is often more difficult, to adjust them to local conditions. More complex appears to be defining and ranking his other duties according to priorities.

The second priority should perhaps be the training of physicians working at the intermediate and primary level concerning the delivery of diabetes care. This includes the condition that it might often not be possible to refer critical cases (children, adolescents, pregnant women with Type 1 diabetes), or cases with complica- tions, to the diabetes center. These physicians should also be trained to pass on some critical information to primary health care officers.

The third order of priority remains the care of diabetic patients, which are referred to the diabetologist from other places or from other service agencies.

Thus, apparently, research and epidemiology have been left to the very end of the priority list. Yet, a simple correct report or documentation of a clinical history is perhaps the best contribution to research and epidemiology in neglected areas of interest.

Too many times, we have experienced the type of adjustment problems that a diabetologist encounters. Very often, he has spent a long period of time abroad in a high-standard diabetes research center. $\mathrm{He}$ has worked in hospitals, clinics and laboratories with the most sophisticated services and technology, and has participated in several research activities. He knows the high value of epidemiology. The temptation to apply most of this knowledge to his new environment is great (often too great), and the impossibility of turning his new job into that of a director of epidemiological or other type of research results in frustration. If he does not adopt the system of priorities as described above, he will fail.

Another frequent, quite understandable temptation is related to his financial situation. Since the health care system in developing countries is often badly organized and poorly paid, he tends to spend part of his precious time taking care of diabetic patients of high economic status, thus reducing his working capacity for the community that needs him so urgently.

Only when all primary health care teams in the area have achieved access to the necessary quantities of insulin and to the most elementary means of running a routine laboratory - and only after an appropriate system of diabetes education has been set up and improved by continuous evaluation - only then has the moment come to consider purchasing a photocoagulator or a cardiotocograph for the hospital acting as the diabetes center. Again, such expensive plans should only be seriously pursued if the optimal use of such instruments can be guaranteed. Too often, one sees such costly apparatuses used for a few hours per week only, or not being used for weeks and months at all, due to inadequate maintenance and service facilities or the lack of spare parts.

The most difficult rationalization (because it goes against our natural tendency towards perfection) is to abstain from the desire to spend money for assay kits and instruments to measure C-peptide, insulin or other serum hormone levels similarly unrelated to the care of diabetic patients as long as funds and personnel are still necessary for improving the diabetes care in the community. One has to evaluate very carefully whether the purchase of every useful device such as a kit for the determination of glycosylated haemoglobin is warranted under the particular circumstances. 
It remains the responsibility of the industrialized, developed societies to assist the developing world in the organization and maintenance of centers of high scientific standards that can formulate, evaluate and promote appropriate models of diabetes care. It is the developed societies which have the means to investigate the different types of diabetes related to malnutrition or a special type of food such as cassava (see above).

We do not know to what extent the motto produced in Alma Ata [30], "Health for everybody in the year 2000 ", may be successfully fulfilled. What we do know is that each member of the health care team in developing countries must respect and obey his own meaning of the duty, "I shall do my best, in the right sense", in order that the generous aim of the WHO be accomplished despite the deep skepticism with which we witness the technological revolution presently infiltrating into every corner of the world without being based upon ethical values.

\section{References}

1. Lambo TD (1981) A new world in the making. Bull Deliv Health Care Diabetics Develop Countries (Zagreb) 2: 2-8

2. Serantes NA (1981) Editorial. Bol Assoc Lat Am Diabetes 30:1-3

3. Bajaj IS (1982) Diabetes nellitus in developing countries. IDF Bull 27: $28-32$

4. Toumilento J, Zimmet P, King H, Pressley M (eds) Diabetes mellitus. Primary health care prevention and control. International Diabetes Federation, London

5. Krall LP, Alberti KGMM (eds) (1982) World book of diabetes in practice. Excerpta Medica, Amsterdam, Holland

6. Tattersall RB (1984) Diabetes in the elderly. A neglected area? Diabetologia 27: 167-173

7. Servain-Schreiber JJ (1980) Le defi mondial. Fayard, Paris

8. Vargas Tentor $F$ (1981) Atención primaria de la salud. Estratégia para extender los servicios a la población marginada. Bol Sanit Panam 90:1-7

9. Ibrahim M (1985) Diabetes care as an integral part of existing primary health care programs in Bangladesh. IDF Bulletin (in press)

10. Afgaonkar SS (1982) Status of diabetes in India. In: Krall LP, Alberti KGMM (eds) World book of diabetes in practice. Excerpta Medica. Amsterdam, pp 167-170

11. Calderón R (1982) The special needs of Latin America in the field of diabetes. Bull Deliv Health Care Diabetics Develop Countries (Zagreb) 3:7-9

12. Instituto Nacional de Estadística y Censos (1984) La pobreza en la Argentina. Buenos Ed, INDEC, Buenos Aires

13. Mella I, Garcia de los Rios M, Barter M, Corrubias IA (1984) Prevalencia de la diabetes en el Gran Santiago. Rev Med Chil 109: $869-875$
14. Comisión ALAD-PLAD (1982) Informe de la Comisión Técnica de Associación Latino-America de Diabetes. Bol Assoc Lat Am Diabetes 32: 3-9

15. Shanghai Diabetes Research Cooperation Group (1980) Diabetes mellitus survey in Shanghai. Chinese Med J 93:663-670

16. Chi-Zhu-sheng, Zhu Xixing, Zhong Xue-li (1983) Some aspects of diabetes in the People's Republic of China. In: Mann JI, Pyörälä $\mathbf{K}$, Teuscher A (eds) Diabetes in epidemiological perspective. Churchill Livingstone, Edinburgh, London, Melbourne, New York, pp 79-96

17. Hazoury Bahlés J, Estrada Muñoz M, Nunes MR, Martinez B, Guzman W (1981) Epidemiología de la diabetes tipo I en Santo Domingo, República Dominicana. Rev Inst Nat Dominic Endocrinol Nutr 6:33-36

18. Vaandrager GJ, Bruining GF, Veenhof FJ, Drayer NM (1984) Incidence of childhood diabetes in the Netherlands: a decrease from north to south over North-Western Europe? Diabetologia 27: 203-206

19. Hamman RF (1983) Diabetes in affluent societies. In: Mann JI, Pyörälä K, Teuscher A (eds) Diabetes in epidemiological perspective. Churchill Livingstone, Edinburgh, London, Melbourne, New York, pp 7-42

20. Mngola EN (1982) Status of diabetes in Africa. In: Krall EP, Alberti KGMM (eds) World Book of Diabetes in Practice 1982. Excerpta Medica, Amsterdam, Holland, pp 163-164

21. Chi Zhi-Sheng (1980) Study of vascular complications of diabetes mellitus in China. IDF Bulletin 25:14-17

22. Hugh Jones P (1955) Diabetes in Jamaica. Lancet 2: 891-897

23. Zuidema PJ (1955) Calcification and cirrhosis of the pancreas in patients with deficient nutrition. Doc Med Geog Troph 7: 229-235

24. Mngola EN (1982) African pancreatic diabetes. In: Krall EP, Alberti KGMM (eds) World book of diabetes in practice 1982. Excerpta Medica, Amsterdam, Holland, pp 176-179

25. Bajaj JS, Agrawal R (1984) Malnutrition diabetes. In: Baba S, Gould MK, Zimmet P (eds) Diabetes mellitus, recent knowledge on aetiology, complications and treatment. Academic Press, Sidney, Australia, pp 73-86

26. Associación Latino-America de Diabetes (1981) Normas de atención al diabético. Edit Hoechst de Argentina, Buenos Aires

27. Arduino F (1983) Manual de tratamiento do diabetes mellitus. Edit Hoechst do Brasil, Rio de Janeiro

28. Associación Latino America de Diabetes (1983) Seminario para la educación diabetológica para el médico general y personal paramédico latinoamericano. Bol Assoc Lat Am Diabetes 33: 6-26

29. Hazoury Bahlés J (1983) Discurso Acto Inauguración Hospital Escuela de Diabetes. Rev Inst Nat Dominic Endocrinol Nutr 8: 3-4

30. World Health Organization (1981) Global strategy for health for all by the year 2000 . WHO Publ Series No.3, World Health Organization, Geneva

Professor Nestor A. Serantes

Chairman of the IDF Regional Council

for Central and South America

Escalada 51

1640 Acassuso

Argentina 